This item was submitted to Loughborough's Research Repository by the author.

Items in Figshare are protected by copyright, with all rights reserved, unless otherwise indicated.

\title{
Efficiency and durability predictions of high performance racing transmissions
}

PLEASE CITE THE PUBLISHED VERSION

http://dx.doi.org/10.4271/2016-01-1852

PUBLISHER

(C) SAE International

VERSION

AM (Accepted Manuscript)

\section{PUBLISHER STATEMENT}

This work is made available according to the conditions of the Creative Commons Attribution-NonCommercialNoDerivatives 4.0 International (CC BY-NC-ND 4.0) licence. Full details of this licence are available at: https://creativecommons.org/licenses/by-nc-nd/4.0/

\section{LICENCE}

CC BY-NC-ND 4.0

\section{REPOSITORY RECORD}

Fatourehchi, Ehsan, Vishak Elisaus, Mahdi Mohammadpour, Stephanos Theodossiades, and Homer Rahnejat. 2019. "Efficiency and Durability Predictions of High Performance Racing Transmissions". figshare. https://hdl.handle.net/2134/20793. 


\title{
Efficiency and Durability Predictions of High Performance Racing Transmissions
}

\author{
Ehsan Fatourehchi, Vishak Elisaus, Mahdi Mohammadpour, Stephanos Theodossiades, Homer Rahnejat
}

Wolfson School, Loughborough University, UK

\begin{abstract}
Efficiency and durability are key areas of research and development in modern racing drivetrains. Stringent regulations necessitate the need for components capable of operating under highly loaded conditions whilst being efficient and reliable. Downsizing, increasing the powerto-weight ratio and modification of gear teeth geometry to reduce friction are some of the actions undertaken to achieve these objectives. These approaches can however result in reduced structural integrity and component durability. Achieving a balance between system reliability and optimal efficiency requires detailed integrated multidisciplinary analyses, with the consideration of system dynamics, contact mechanics/tribology and stress analysis/structural integrity.
\end{abstract}

This paper presents an analytical model to predict quasi-static contact power losses in lubricated spur gear sets operating under the Elastohydrodynamic regime of lubrication. Tooth Contact Analysis (TCA) is used to predict variations in contact loads, local surface curvature and rolling and sliding velocities. This is combined with an extrapolated oil film thickness formula available in literature, to predict instantaneous lubricant film thickness and sub-surface stresses. Subsequently, viscous and boundary friction are estimated, enabling calculation of power losses.

The presented methodology has been used to investigate the effects of parabolic tip relief on power loss and induced sub-surface stresses. The results of this investigation are also presented.

\section{Introduction}

Transmissions of high performance racing vehicles can routinely transmit contact loads in excess of $20 \mathrm{kN}$. Thus, small variations in gear meshing efficiency can have a significant effect on the magnitude of power loss. These transmissions are also particularly compact, yielding highly concentrated tooth meshing contacts. Coupled with relatively high rolling and sliding velocities, small variations in the contact footprints can result in noticeable change in transmission efficiency. A methodical approach capable of predicting the parameters which affect transmission efficiency in such a system is the key to making informed engineering decisions ranging from appropriate geometrical modifications to lubrication strategies.

During operation, loaded gear teeth routinely experience contact pressures exceeding 1-2 GPa. This results in significant piezo-viscous action, with the lubricant behaving as an amorphous solid, whilst the solid bodies in contact undergo elastic deformation, a condition referred to as Elastohydrodynamic Lubrication (EHL)

Reliable estimation of lubricant film thickness is required for accurate evaluation of contact friction, comprising that generated by the shear of a thin lubricant film, as well as boundary friction due to potential asperity interaction on the contiguous rough surfaces. Ertel [1] was the first to incorporate both the localised elastic deformation of mating surfaces and the piezo-viscous action of the lubricant. He solved the piezo-viscous hydrodynamic problem while assuming that the surfaces were elastically deformed in accord with the small strain Hertzian contact theory.

Dowson and Higginson [2] produced a series of computed solutions over a wide range of speeds, loads and material properties and derived regression equations expressed in terms of three non-dimensional groups to predict minimum film thickness for line contact configuration, such as a rigid roller against a semi-infinite elastic solid. In the 1960s, Archard and Cowking [3] and Ranger et al [4] produced full numerical solutions of the 2D EHL problem for point contact. Hamrock and Dowson [5] extended these to the elliptical contact footprint geometry. They provided extrapolated regression formulae for central and minimum lubricant film thickness. Chittenden et al. [6] later extended the range of geometrical configurations to include the effect of angled entrainment flow into the contact, which occurs in some gearing applications such as those of hypoid gear pairs. In such contacts significant side leakage flow occurs away from the main flow in the direction of entraining motion along the semi-minor half-width of the elliptical point contact as demonstrated experimentally by Thorp and Gohar [7]. Jalali-Vahid et al. [8] provided a detailed numerical analysis using isothermal Newtonian EHL, which agreed with the interferometric studies of Thorp and Gohar [7], thus underpinned the significance of side leakage flow from such elliptical point contact geometries, which affect the film thickness, thus the estimated friction.

Early solutions assumed fully flooded inlets, with isothermal Newtonian conditions, and usually at low to medium contact loads, owing to the limitations in computational power at the time. The issue of inlet starvation required use of inlet reverse flow boundaries such as those of Tipei [9] which were confirmed by the experimental works by Johns-Rahnejat and Gohar [10] and recently through combined experimental and numerical investigation in [11], which show reduced film thickness, thus increasing friction as would be expected. These conditions in transmission systems at high load and increased shear rate lead to thin thermo-elastohydrodynamic conditions investigated in some detail by Evans and Johnson [12].

Evans and Johnson [12] constructed traction maps for lubricants of known rheological properties in which different regimes of shear behaviour are described, depending on the operating conditions; load, speed and temperature. The lubricant behaviour was deemed to be either Newtonian, Eyring, viscoelastic, or elastic-plastic. A series of expressions for traction coefficients was derived for each of these regimes with which viscous friction of the lubricant can be evaluated.

Prediction of the film thickness using existing EHL formulations requires prior knowledge of instantaneous equivalent radii of curvature of meshing teeth pairs, as well as the sliding and rolling velocities of the contacting surfaces.

Tooth Contact Analysis (TCA) is employed for this purpose, which comprises a combination of finite element technique and Hertzian 
theory in order to obtain accurate representation of gear teeth contacting geometry as well as the calculation of the necessary kinematic and loading parameters for a quasi-statically loaded teeth pair. Although the classical methods of gear contact analysis are faster and computationally efficient [13], they do not take into account the effect of complex tooth modifications.

Numerous studies have been carried out in an effort to predict transmission efficiency. Mohammadpour et al. [14] developed a tribodynamic model to study the transient nature of transmission efficiency and $\mathrm{NVH}$ (noise, vibration and harshness) performance under various driving conditions. They combined multi-body dynamics with an analytical approach for non-Newtonian lubricant behavior in order to determine transmission efficiency. Xu et al. [15] carried out a parametric studies using a numerical thermal EHL model to assess the effect of gear geometry, tooth modifications, operating conditions, lubricant properties, manufacturing and assembly errors, and surface finish on mechanical efficiency of gears. Results of this study were validated by comparing the predictions with experimental measurements made on a spur gear rig.

The current study incorporates TCA and analytical non-Newtonian thermo-elastohydrodynamics (TEHL) to predict the instantaneous lubricant film thickness and friction in gear teeth contacts through typical meshing cycles. The simulated conditions are typical of high performance racing transmissions during severe conditions of a race. The study also assesses the effect of gear tip relief and crowning on power losses over a single meshing cycle. Structural integrity of teeth under maximum contact pressures are also ascertained using the maximum reversing cyclic orthogonal sub-surface stresses.

\section{Methodology}

The method integrates TCA, analytical TEHL and sub-surface stress analysis. The instantaneous radii of curvature, rolling and sliding velocities and normal load are obtained for a complete meshing cycle. These parameters form the input to the formulations for the instantaneous estimations of EHL film thickness, viscous friction, boundary friction and stress distributions.

\section{Film Thickness}

The lubricant film thickness under the instantaneous operating conditions is obtained using Chittenden et al. [6] lubricant film thickness expression:

$h_{c 0}^{*}=4.31 U_{e}^{0.68} G_{e}^{0.49} W_{e}^{-0.073}\left\{1-\exp \left[-1.23\left(\frac{R_{y}}{R_{x}}\right)^{2 / 3}\right]\right\}$

where, the prevailing contact conditions are represented by the following non-dimensional parameters:

$W_{e}=\frac{\pi W}{2 E_{r} R_{x}^{2}}, U_{e}=\frac{\pi \eta_{0} U_{r}}{4 E_{r} R_{x}}, G_{e}=\frac{2}{\pi}\left(E_{r} \alpha\right)$ and $h_{c 0}^{*}=\frac{h_{\mathrm{c} 0}}{R_{x}}$

where, $W$ is the normal load, $E_{r}$ is the reduced elastic modulus of contact, $R_{x}$ is the radii of curvature along the lubricant entrainment direction, $\eta_{0}$ is the lubricant viscosity, $U_{r}$ is the speed of entraining motion, $\alpha$ is the pressure viscosity coefficient, and $h_{\mathrm{c} 0}$ is the central film thickness.

\section{Viscous Friction}

Evans and Johnson [12] implemented a method to analyse viscous friction in EHL contacts. With the high loads experienced by gears in racing transmissions, the lubricant in the mesh teeth-pair contacts operates in the Eyring traction regime. Consequently, the coefficient of friction is calculated using [12]:

$\mu=0.87 \alpha \tau_{0}+1.74 \frac{\tau_{0}}{\bar{p}} \ln \left[\frac{1.2}{\tau_{0} h_{c 0}}\left(\frac{2 K \eta_{0}}{1+9.6 \xi}\right)^{\frac{1}{2}}\right]$

where, $\tau_{0}$ is the lubricant Eyring stress, $\bar{p}$ is the average pressure at the contact point, $K$ is the lubricant thermal conductivity, and $\xi$ is given by:

$\xi=\frac{4}{\pi} \frac{K}{h_{c 0} / R}\left(\frac{\bar{p}}{E^{\prime} R K^{\prime} \rho^{\prime} c^{\prime} U_{r}}\right)^{1 / 2}$

where, $R$ is the contact radii of curvature, $E^{\prime}$ is the reduced elastic modulus, $K^{\prime}, \rho^{\prime}$, and $c^{\prime}$ are the thermal conductivity, density, and specific heat capacity of the solid.

The generated friction due to viscous shear of the lubricant film is expressed as:

$f_{v}=\mu W$

\section{Boundary Friction}

The thin lubricant films in the meshing contacts of loaded gear teeth pairs in racing transmissions are comparable to the roughness of surface asperities. Consequently, asperity interaction and therefore boundary friction is to be expected.

Greenwood and Tripp [16] developed a method to evaluate the generated boundary friction as the result of direct interaction of asperities on the counter face contacting surfaces. The method assumes a Gaussian height distribution of surface asperities. When mixed or boundary regimes of lubrication occur, Stribeck's oil film parameter: $1<\lambda=\frac{h_{c 0}}{\sigma}<2.5$, which is updated at each time step based on the estimated EHL film thickness, specifies the fraction of the load carried by the asperities in the apparent contact area, $A$ [16]:

$W_{a}=\frac{16 \sqrt{2}}{15} \pi(\xi \beta \sigma)^{2} \sqrt{\frac{\sigma}{\beta}} E^{\prime} A F_{5 / 2}(\lambda)$

where, $\beta$ is the average asperity tip radius, $\sigma$ is the composite RMS surface roughness, and the statistical function $\mathrm{F}_{5 / 2}(\lambda)$ for a Gaussian distribution of asperities is obtained as [17]:

$\mathrm{F}_{5 / 2}=$

$\begin{cases}-0.004 \lambda^{5}-0.057 \lambda^{4}-0.29 \lambda^{3}-0.784 \lambda^{2}-0.784 \lambda-0.617 & \text { for } \lambda<2.5 \\ 0 ; & \text { for } \lambda \geq 2.5\end{cases}$

The roughness parameter $(\xi \beta \sigma)$ for steel surfaces is generally in the range $0.03-0.07 . \sigma / \beta$ is a representation of average asperity slope and is in the range of $10^{-4}$ to $10^{-2}$ [18]. In the current study, it is assumed that $\xi \beta \sigma=0.055$ and $\sigma / \beta=10^{-3}$. 
Asperity friction should be considered in mixed and boundary regimes of lubrication. A thin adsorbed film exists at the summit of the asperities or is entrapped in their inter-spatial valleys. This thin adsorbed film is subjected to non-Newtonian shear, thus boundary friction $f_{b}$ is given as [18]:

$$
f_{b}=\tau_{L} A_{a}
$$

where, $A_{a}$ is the asperity area and $\tau_{L}$ is the lubricant's limiting shear stress [19]:

$\tau_{L}=\tau_{0}+\varepsilon P_{m}$

where, $\varepsilon$ is the slope of the lubricant limiting shear stress-pressure, and the mean (Pascal) pressure $\mathrm{P}_{\mathrm{m}}$ is:

$P_{m}=\frac{W_{a}}{A_{a}}$

The asperity contact area is expressed as [16]:

$A_{a}=\pi^{2}(\xi \beta \sigma)^{2} A F_{2}(\lambda)$

The statistical function $F_{2}(\lambda)$ is calculated as [18]:

$F_{2}(\lambda)=$

$\begin{cases}-0.002 \lambda^{5}-0.028 \lambda^{4}-0.173 \lambda^{3}+0.526 \lambda^{2}-0.804 \lambda-0.500 & \text { for } \lambda<2.5 \\ 0 ; & \text { for } \lambda \geq 2.5\end{cases}$

\section{Power Loss}

The instantaneous power loss is determined by taking into account the calculated viscous and boundary friction contributions as:

$P_{\text {loss }}=\left(f_{v}+f_{b}\right) U_{s}$

where, $U_{S}$ is the sliding velocity of the contact.

\section{Sub-surface Stresses}

The main concern with respect to structural integrity and reliability of gearing transmission is fatigue spalling resulting from sub-surface stress field. Figure 1 shows an elastic half-space loaded over the strip $(-\mathrm{b}<\mathrm{x}<\mathrm{a})$ by normal pressure $\mathrm{p}(\mathrm{x})$ and tangential traction $\mathrm{q}(\mathrm{x})$ distributed in any arbitrary manner.

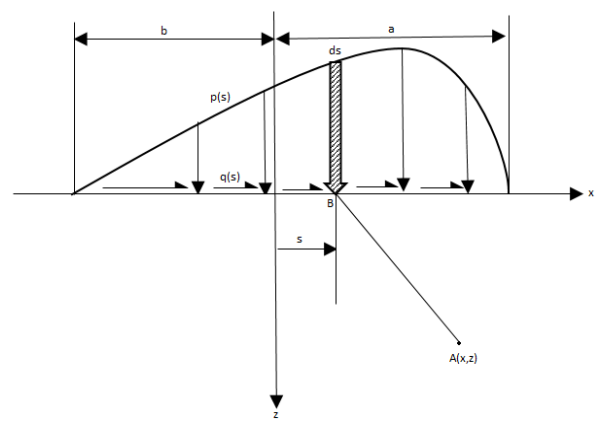

Figure 1. Normal pressure and tangential traction distribution over the solid surface (after Johnson [20])

Page 3 of 8
The sub-surface stress field induced by $\mathrm{p}(\mathrm{x})$ and $\mathrm{q}(\mathrm{x})$ at any point $\mathrm{A}$ within the body of contacting solids is found according to Johnson [20] as:

$\sigma_{x}=-\frac{2 z}{\pi} \int_{-b}^{a} \frac{p(s)(x-s)^{2} d s}{\left[(x-s)^{2}+z^{2}\right]^{2}}-\frac{2}{\pi} \int_{-b}^{a} \frac{q(s)(x-s)^{3} d s}{\left[(x-s)^{2}+z^{2}\right]^{2}}$

$\sigma_{z}=-\frac{2 z^{3}}{\pi} \int_{-b}^{a} \frac{p(s) d s}{\left[(x-s)^{2}+z^{2}\right]^{2}}-\frac{2 z^{2}}{\pi} \int_{-b}^{a} \frac{q(s)(x-s) d s}{\left[(x-s)^{2}+z^{2}\right]^{2}}$

$\tau_{x z}=-\frac{2 z^{2}}{\pi} \int_{-b}^{a} \frac{p(s)(x-s) d s}{\left[(x-s)^{2}+z^{2}\right]^{2}}-\frac{2 z}{\pi} \int_{-b}^{a} \frac{q(s)(x-s)^{2} d s}{\left[(x-s)^{2}+z^{2}\right]^{2}}$

where, in accord with the Hertzian theory:

$p(x)=\frac{2 W}{\pi a^{2}}\left(a^{2}-x^{2}\right)^{1 / 2}$

and the Hertzian circular footprint radius is:

$a^{2}=\frac{4 W R}{\pi E_{r}}$

The maximum pressure is:

$p_{0}=\left(\frac{W E_{r}}{\pi R}\right)^{1 / 2}$

For bearings and gears, the determining sub-surface stress component, generally regarded as the main determining cause of cyclic fatigue failure of contacting pairs, is the reversing orthogonal shear stress, given by equation (14). These occur in depth closer to the contacting surface with a larger double amplitude (cyclic tensile-compressive). The cyclic nature causes the bulk material to be sheared in one direction and then in the opposite sense. The alternating shear stress field, $\tau_{z x}$ occur in pairs at $90^{\circ}$ to each other in the auxiliary planes [21]. The equivalent stress, $\sigma_{e}$ with the alternating shear stress hypothesis is [22]:

$\sigma_{e}=2\left|\tau_{z x \max }\right|$

where, the double amplitude for $\sigma_{e} \approx 0.5$ and remains approximately the same with additional surface traction [23]. The onset of yielding according to the alternating shear stress hypothesis is when the equivalent stress reaches half the yield stress of the material (i.e. structural integrity is assured, when): $\sigma_{e}<\frac{1}{2} \sigma_{y}$ ). 


\section{Results and Discussion}

In this study the effect of gear teeth tip relief on power loss is investigated for a typical meshing cycle. Table 1 lists the relevant gear data and operating conditions. Table 2 provides the lubricant properties.

Table 1. Pinion and gear parameters

\begin{tabular}{|l|l|}
\hline Module $(\mathrm{mm})$ & 3.8 \\
\hline Number of teeth (pinion:gear) & $13: 35$ \\
\hline Normal pressure angle $\left({ }^{\circ}\right)$ & 28 \\
\hline Face width $(\mathrm{mm})$ & 13.5 \\
\hline Pinion speed $(\mathrm{RPM})$ & 11200 \\
\hline Pinion torque $(\mathrm{Nm})$ & 392 \\
\hline
\end{tabular}

Table 2. Physical properties of the lubricant and solids

\begin{tabular}{|l|l|}
\hline Pressure viscosity coefficient $\left(\mathrm{Pa}^{-1}\right)$ & $1.05 \times 10^{-8}$ \\
\hline $\begin{array}{l}\text { Lubricant Atmospheric dynamic } \\
\text { viscosity at } 100^{\circ} \mathrm{C}(\mathrm{mPa} . \mathrm{s})\end{array}$ & 4.04 \\
\hline Lubricant Eyring stress $(\mathrm{MPa})$ & 2 \\
\hline Thermal conductivity of fluid $(\mathrm{W} / \mathrm{mK})$ & 1600 \\
\hline Heat capacity of fluid $(\mathrm{J} / \mathrm{kg} \mathrm{K})$ & 0.140 \\
\hline $\begin{array}{l}\text { Modulus of elasticity of contacting solid } \\
\text { (GPa) }\end{array}$ & 1.999 \\
\hline Poisson's ratio of contacting solids $(-)$ & 0.3 \\
\hline Density of contacting solids $\left(\mathrm{kg} / \mathrm{m}^{3}\right)$ & 7850 \\
\hline $\begin{array}{l}\text { Thermal conductivity of contacting } \\
\text { solids }(\mathrm{W} / \mathrm{m} \text { K) }\end{array}$ & 46 \\
\hline $\begin{array}{l}\text { Heat capacity of contacting solids }(\mathrm{J} / \mathrm{kg} \\
\mathrm{K})\end{array}$ & 470 \\
\hline RMS composite Surface roughness $(\mu \mathrm{m})$ & 0.4 \\
\hline
\end{tabular}

\section{Effect of Profile Modification - Parabolic Tip Relief}

At high loads, increased tooth deformation can deteriorate the transmission error. Under these conditions, gear teeth tip relief through removal of material ensures smoother action. Tip relief, the magnitude of which is given by the amount of deviation from the involute profile on the gear tip diameter (Figure 2), has become a means of reducing the effects of transmission error in high-speed gear sets. The application of tip relief in involute teeth can also reduce impact loads as teeth pairs come into contact.

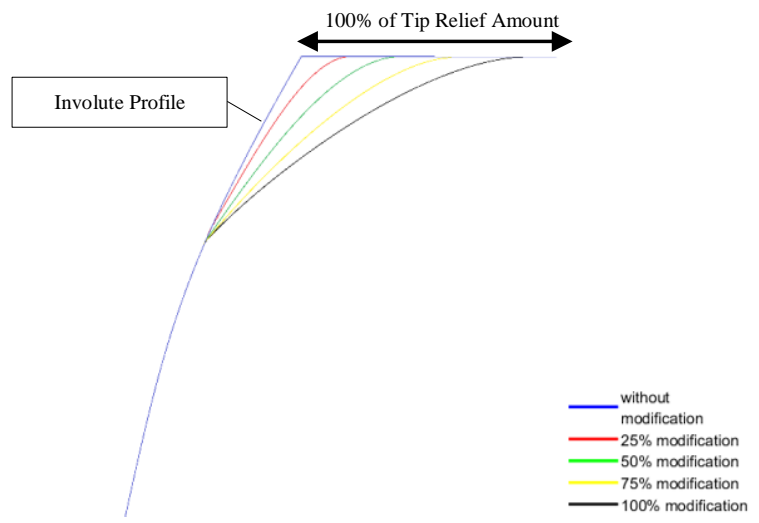

Figure 2. Parabolic tip relief (not to scale)

In order to investigate the effect of tip relief (of parabolic shape) in spur gears, different extents of relief are applied to the gear pair model for which TCA is conducted. Table 3 shows the amount of tip relief for different considered cases.

Table 3. Amount of tip relief for different case study

\begin{tabular}{|l|l|}
\hline Scenario & Amount of tip relief \\
\hline 1 & $100 \%$ \\
\hline 2 & $75 \%$ \\
\hline 3 & $50 \%$ \\
\hline 4 & $25 \%$ \\
\hline 5 & $0 \%$ \\
\hline
\end{tabular}

Figure 3 illustrates the contact load variation for a teeth pair over a normalised meshing cycle (zero on the abscissa denotes the onset of meshing and 1 the end of a meshing cycle) for the different scenarios considered.

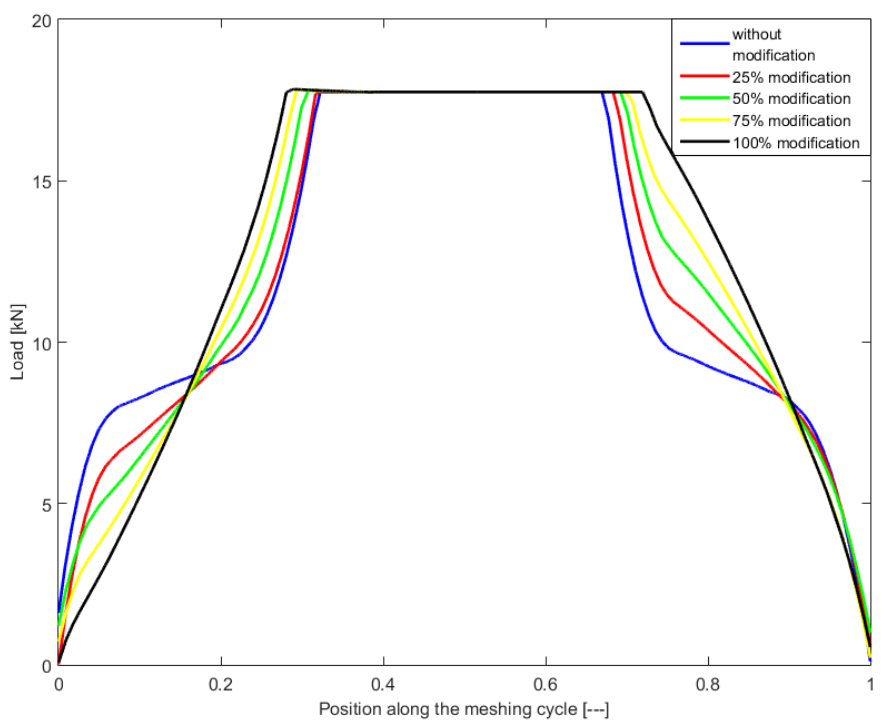

Figure 3. Load distribution along the meshing cycle for different amounts of tip relief

Page 4 of 8 
As the extent of tip relief increases, loading at the beginning and at the end of mesh becomes more gradual. However, increasing the tip relief also results in a longer duration of teeth pair contact. This is characterized by the increase in duration of the meshing cycle for which the total gear load $(17,750 \mathrm{~N})$ is carried by a single pair of teeth in mesh. It is during single teeth pair contact that the highest contact loads are generated. This is also when the highest critical sub-surface stresses occur.

Figure 4 shows the film thickness variation along the meshing cycle for the different considered cases.

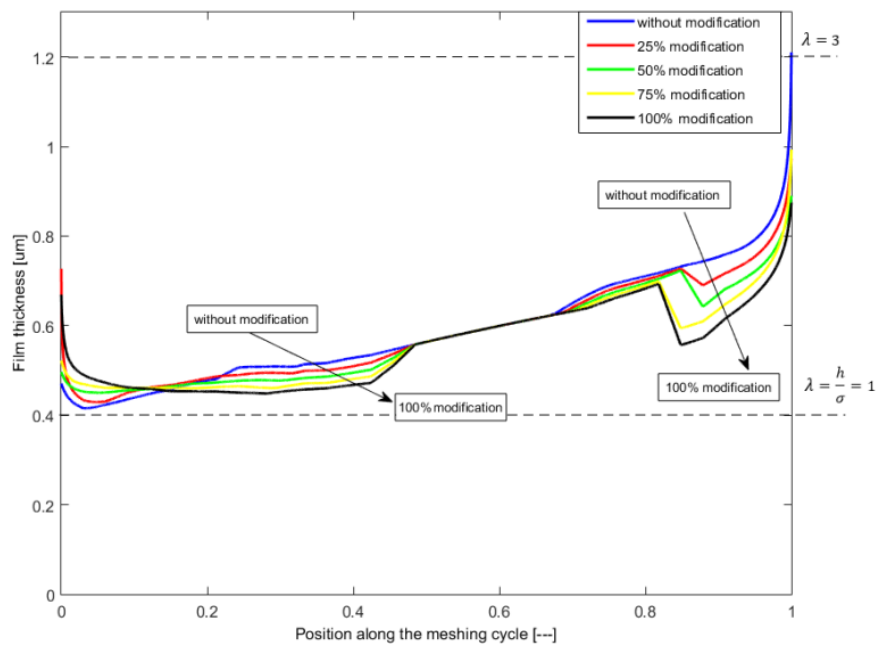

Figure 4: Film thickness along the meshing cycle for different amounts of tip relief

The predicted film thickness ranges between 0.4 to $1.2 \mu \mathrm{m}$. As the Stribeck oil film parameter $\lambda$ is between unity and 3 , a mixed regime of lubrication would be expected. In fact, Figure 4 shows that the teeth pair contact is under $\alpha$ mixed regime of lubrication for the entire duration of the meshing cycle.

At the start of the meshing cycle, the tip of the driven tooth comes into contact with the root of the driving tooth. During the first $40 \%$ of the meshing cycle (0-0.4 on the abscissa), the contact moves along the tip relief region on the driven gear. Figure 4 shows that as the amount of tip relief is increased, a corresponding reduction in film thickness is observed after the first $20 \%$ of the meshing cycle. However, a significant gain in the film thickness occurs at the start of the meshing cycle which is the most critical region where the thinnest film thickness is noted. Therefore, generally an increase in tip relief can improve film thickness in the critical parts of the meshing cycle.

Figure 5 shows the instantaneous power loss along the meshing cycle for the five different investigated cases. The total power loss is calculated, taking into account the effects of leading and trailing teeth pairs.

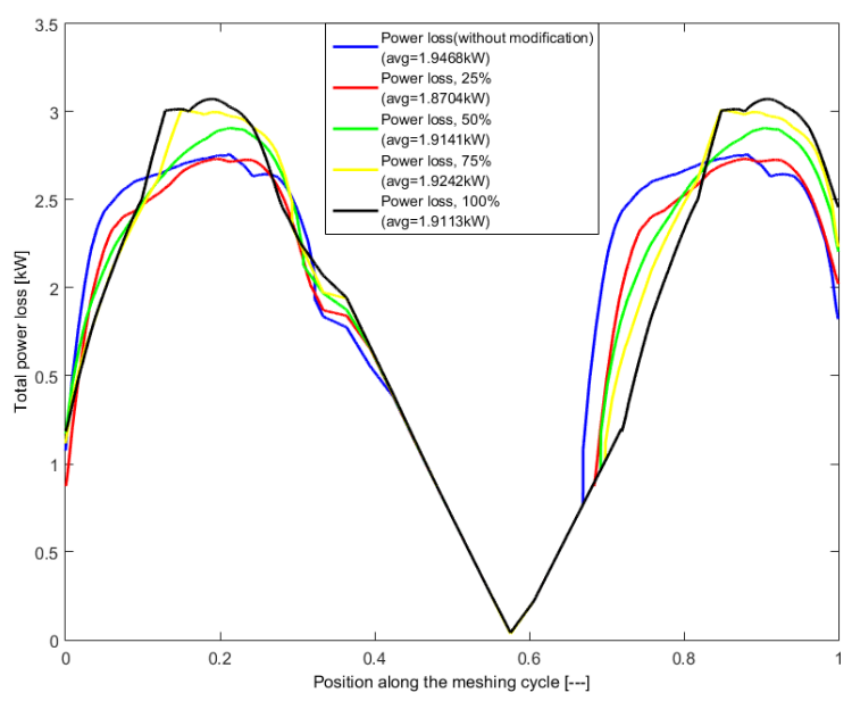

Figure 5. Total power loss along the meshing cycle for different amounts of tip relief

The variation in lubricant film thickness and surface velocities brought about by different applied tip relief varies the instantaneous power losses. Using this method, Figure 5 shows that the average power loss over the meshing cycle decreases when a tip relief is applied. However, the largest reduction in power loss is observed at $25 \%$ tip relief.

Figure 6 illustrates the variation of maximum shear stress along the meshing cycle for different applied tip relieves.

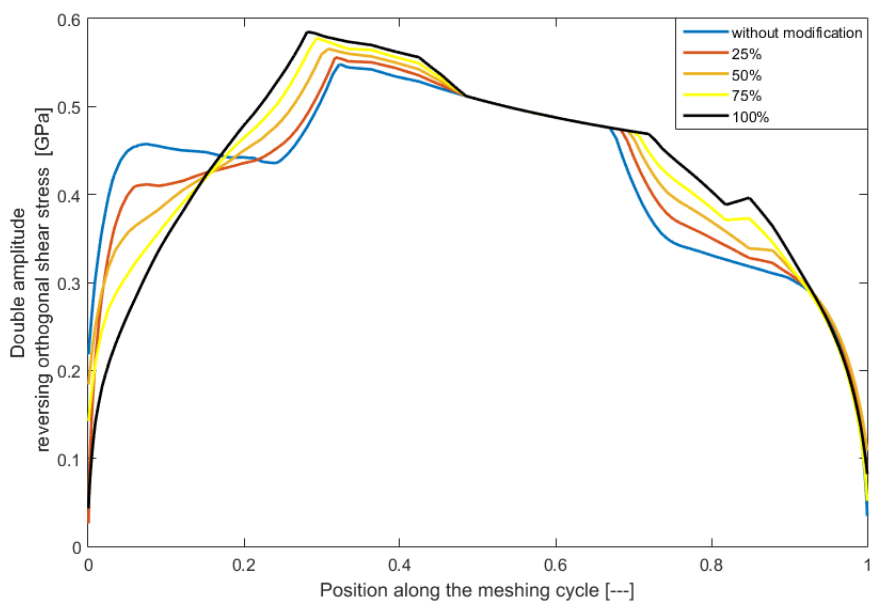

Figure 6. Double amplitude reversing orthogonal shear stress along the meshing cycle for different amounts of tip relief 
The yield stress of the teeth steel is $1.1 \mathrm{GPa}$, thus the double amplitude of the alternating shear stress (i.e. the equivalent stress) should not exceed $550 \mathrm{MPa}$ according to the shear stress criterion described above. It can be seen that the equivalent stress remains below this limit, only approaching the same in parts of the meshing cycle. Interestingly this occurs in the earlier parts of the cycle, somewhat away from the tip relief region. With increasing the extent of tip relief the effect of alternating shear stresses becomes more pronounced, but one should note that some degree of work hardening occurs with increased compression as well, thus the results show a sufficient degree of fatigue resistance even under such highly loaded conditions.

\section{Effect of Crowning}

Involute spur gears are very sensitive to gear misalignments which can result in the edge loading of the teeth flanks. Several investigators such as; Seol and Kim [24], Dudley [25] and Simon [26] have investigated the improvements in the meshing contact distribution of misaligned spur gears through crowning.

Using the methods presented in this study, the effect of crowning spur gears on the power loss and durability is investigated. Table 4 shows the amount of crowning applied for each scenario studied. All crowning considered in this study is symmetric.

Table 4. Amount of crowning for different case study

\begin{tabular}{|l|l|}
\hline Scenario & Amount of crowning \\
\hline 1 & $100 \%$ \\
\hline 2 & $75 \%$ \\
\hline 3 & $50 \%$ \\
\hline 4 & $25 \%$ \\
\hline
\end{tabular}

Figure 7 illustrates the varying amounts of crowning used. The local contact geometry and kinematic parameters have been included as those occurring at the centre of the tooth flank.

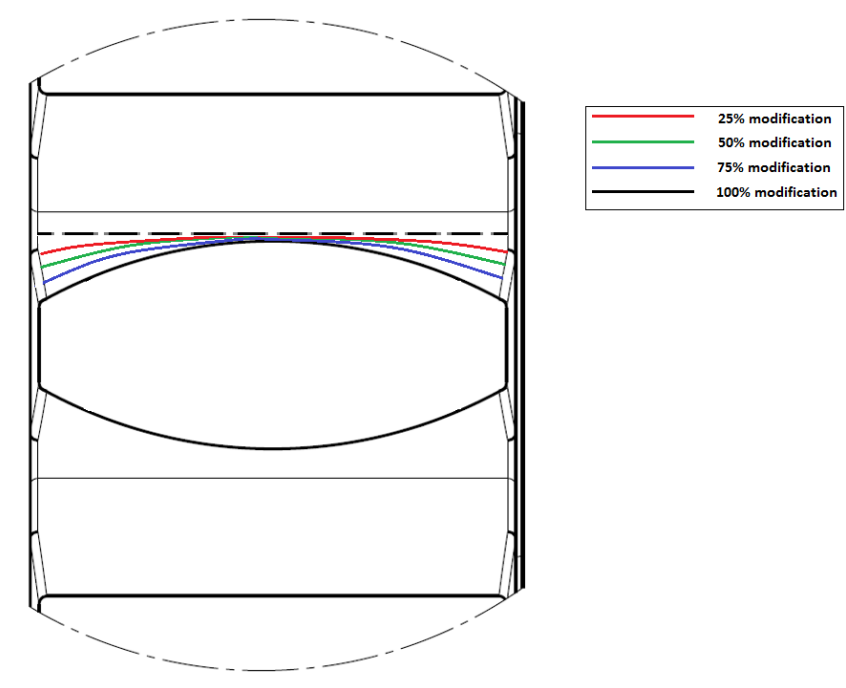

Figure 7: Amount of applied crowning (not to scale) - top-down crosssectional view. Dashed line represents the un-modified gear tooth
Figure 8 shows the variation in instantaneous power loss for cases with different crowning for the duration of a meshing cycle.

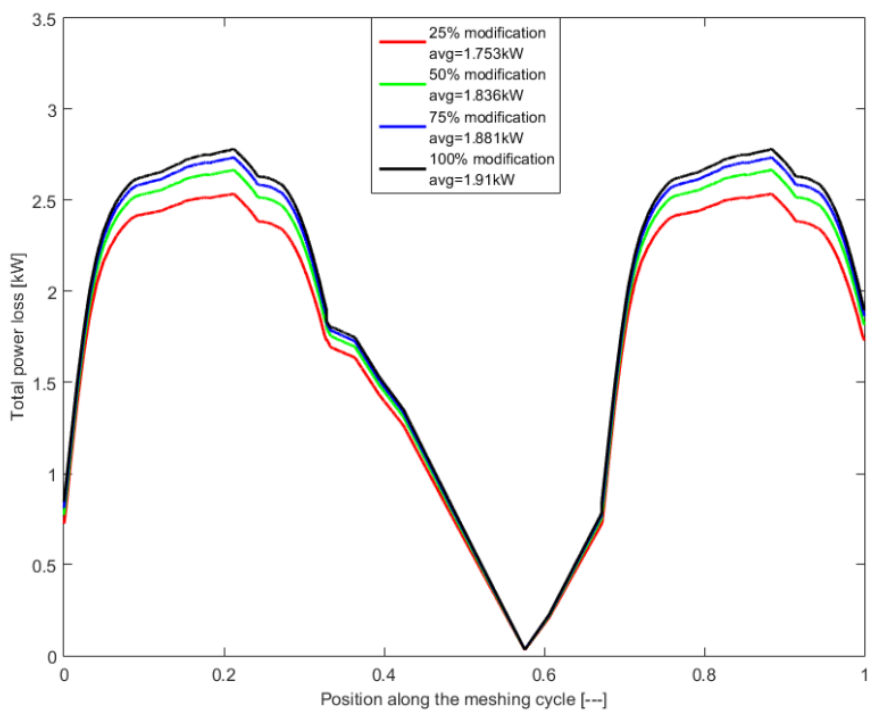

Figure 8. Total power loss along the meshing cycle for different values of crowning

The total power loss increases slightly with increased crowning. However, crowning concentrates to the centre of the flank region. This reduces the magnitude of pressure spikes which occur at the flank edges due to their finite line contact geometry. The presence of pressure spikes tends to inhibit the flow of lubricant in their vicinity, causing islands of minimum lubricant film thickness at the edges of the contact. This is seen in finite line contact geometries, for example that of rolling element bearings to raceways [27]. These are not included in the current analysis.

For the case of crowing, Figure 9 shows the variation of the equivalent stress remains the same for all the cases studied.

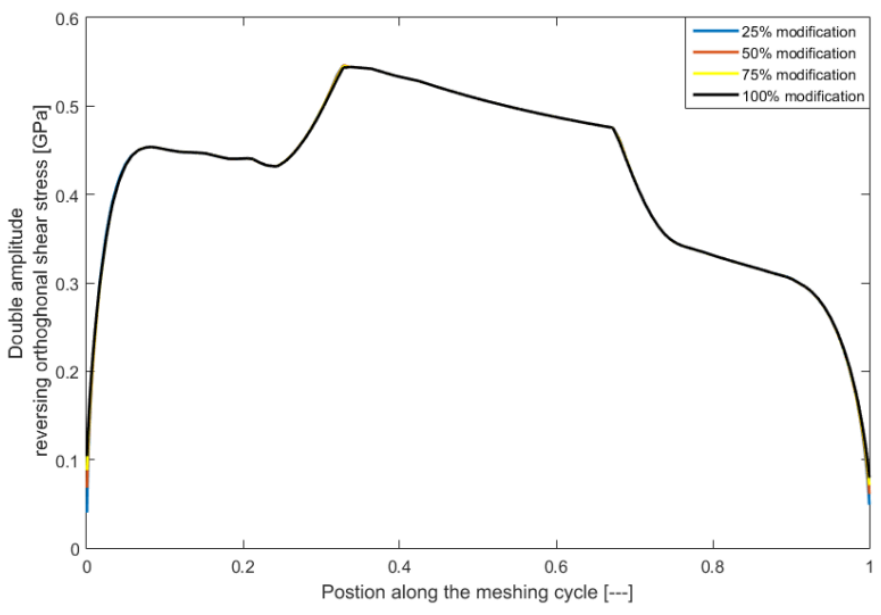

Figure 9. Double amplitude reversing orthogonal shear stress along the meshing cycle for different values of the crowning

Of course, a two-dimensional analysis (along the direction of sliding and into the sub-surface layers) is carried out here. In order to study the effect of crowning on sub-surface stresses, three-dimensional numerical model would be required in order to take into account

Page 6 of 8 
traction and changes in the contact footprint shape in the lateral direction as well.

\section{Conclusions}

The study investigates the effect of parabolic tip relief and crowning modifications on the power loss of high performance gears, as well as on sub-surface stresses. The presented analytical model is time efficient, simulating a meshing cycle of spur gear pair in about $10 \mathrm{CPU}$ seconds.

The following conclusions are made:

1. Increasing the amount of tip relief enhances the lubricant film thickness for the initial $20 \%$ of the meshing cycle. This region is usually expected to have the thinnest lubricant films as the TCA outlines the lowest rolling velocity (lubricant entrainment velocity) in this region relative to the remainder of the meshing cycle.

2. Increasing the extent of tip relief has shown to reduce lubricant film thickness in subsequent parts of the meshing cycle. This observation correlates with observed reduction in the rolling velocity which occurs as the mesh point moves along regions of tip relief. While this would be detrimental to contact efficiency, the power loss estimations presented in this study suggest an optimum amount of profile modification.

3. Increasing tip relief exacerbates the sub-surface shear stresses for the mid part of the meshing cycle. This is the most critical region due to the higher contact load there. Thus, although tip relief improves the fatigue resistance elsewhere in the meshing cycle, the aforementioned rise in sub-surface shear stresses should be considered as a limiting application constraint.

4. Increasing levels of crowning can adversely affect the power losses in the aligned involute spur gears. Despite this drawback, crowning reduces the magnitude of pressure spikes at the edges of the gear flank, which is not investigated in this paper.

\section{References}

1. Ertel, A.N., "Hydrodynamic lubrication based on new principles," Akad. Nauk. SSSR. Prikadnaya Mathematica I Mekhanika, 3(2): 41-52, 1939.

2. Dowson, D. and Higginson, G.R., "A numerical solution to the elastohydrodynamic problem," Proc Instn Mech Engrs., J Mech. Eng. Sci., 1: 6-15 1959.

3. Archard, J.F. and Cowking, E.W., "Elastohydrodynamic lubrication at point contacts", Proc. IMechE, J. Mech. Eng. Sci., 180, 1965

4. Ranger, A.P., Ettles, C.M.M. and Cameron, A., "The solution of point contact EHL problem”, Proc. Roy. Soc., Ser. A,346, 1975

5. Hamrock, B.J. and Dowson, D., "Isothermal elastohydrodynamic lubrication of point contacts, Part II - Ellipticity parameter results," Trans. ASME, J. Lubn. Tech., (98): 375-383, 1976.

6. Chittenden, R. J. Dowson, D., Dunn, J. F. and Taylor, C. M., “A theoretical analysis of the isothermal elastohydrodynamic lubrication of concentrated contacts. II. General Case, with lubricant entrainment along either principal axis of the Hertzian contact ellipse or at some intermediate angle," Proc. Roy. Soc., Ser. A, 397:271-294, 1985.

7. Thorp, N. and Gohar, R. Hydrodynamic friction in elliptical and circular point contacts. Trans. ASME, J. Lubric. Technol., 94, 199-208, 1971
8. Jalali-Vahid, D., Rahnejat, H., Gohar, R. and Jin, Z.M., "Prediction of oil film thickness and shape in elliptical point contacts under combined roling and sliding motion", Proc. IMechE, J. Engineering Tribology, 214, 427-437, 2000

9. Tipei, N. "Boundary conditions of a viscous flow between surfaces with rolling and sliding motion", J. Tribology 90 , no. 1 (1968): 254-261.

10. Johns-Rahnejat, P. M., and R. Gohar. "Measuring contact pressure distributions under elastohydrodynamic point contacts." Tribotest 1, no. 1 (1994): 33-53.

11. Mohammadpour, M., Johns-Rahnejat, P.M. Rahnejat, H. and Gohar, R., "Boundary conditions for elastohydrodynamics of circular point contacts." Tribology Letters, 53(1), (2014): 107118.

12. Evans C.R. and Johnson K.L., "Regimes of traction in elastohydrodynamic lubrication," Proc Instn Mech Engrs, 200(C5): 313-324, 1986

13. Mohammadpour, M., Mirzaee, I., and Khalilarya, S. "A mathematical-numerical model to calculate load distribution, contact stiffness and transmission error in involute spur gears." ASME/IDETC 2009, California, USA

14. Mohammadpour M, Theodossiades S, Rahnejat H. and Kelly P., "Transmission efficiency and noise, vibration and harshness refinement of differential hypoid gear pairs", Proceedings of the Institution of Mechanical Engineers, Part K: Journal of Multibody Dynamics. 2014, 228(1): 19-33

15. Xu H, Kahraman A, Anderson NE, Maddock DG. Prediction of mechanical efficiency of parallel-axis gear pairs. Journal of Mechanical Design. 2007,29(1):58-68.

16. Greenwood J.A., and Tripp J.H., "The contact of two nominally flat rough surfaces," Proc Instn Mech Engrs 185: 625-633, 1970.

17. Mohammadpour, M., Theodossiades, S. and Rahnejat, H., "Transient mixed non-Newtonian thermo-elastohydrodynamics of vehicle differential hypoid gears with starved partial counterflow inlet boundary" Proc. IMechE, Part J: Journal of Engineering Tribology, 2014, 228(10): 1159-1173

18. Mohammadpour, M., Rahmani, R. and Rahnejat, H., "Effect of cylinder deactivation on the tribo-dynamics and acoustic emission of overlay big end bearings", Proceedings of the Institution of Mechanical Engineers, Part K: Journal of Multibody Dynamics. 2014, 228(2): 138-151

19. Briscoe BJ, Evans DC. The shear properties of LangmuirBlodgett layers. InProceedings of the Royal Society of London A: Mathematical, Physical and Engineering Sciences 1982, 380(1), No. 1779 , pp. 389-407

20. Johnson, K. L. Contact mechanics. Cambridge university press, 1987.

21. Johns-Rahnejat, P. M., and R. Gohar. "Point contact elastohydrodynamic pressure distribution and sub-surface stress field." In Tri-Annual Conference on Multi-Body Dynamics: Monitoring and Simulation Techniques. 1997.

22. Johns-Rahnejat, P.M., "Pressure and stress distribution under elastohydrodynamic point contacts", $\mathrm{PhD}$ thesis, Imperial College, London, 1988

23. Gohar, R. and Rahnejat, H., "Fundamentals of Tribology", Imperial College Press, London, 2008.

24. Seol, I. H., and Kim, D. H., "The Kinematics and Dynamic Analysis of Crowned Spur Gear Drive," Comput. Methods Appl. Mech. Eng., 167:109-118, 1998.

25. Dudley, D. W. Dudley's gear handbook. 2nd Edition, McGrawHill, U.S.A., New York, 1992.

26. Simon, V., "'Optimal Tooth Modifications for Spur and Helical Gears,' ASME Journal of Mech. Trans. Auto. Design, 111:611$615,1989$.

Page 7 of 8 
27. Kushwaha, M., Rahnejat, H. and Gohar, R., "Aligned and misaligned contacts of rollers to races in elastohydrodynamic finite line conjunctions", Proc. IMechE, Part C: J. Mech. Engineering Science 216(11), 2002, pp. 1051-1070.

\section{Contact Information}

Dr. Mahdi Mohammadpour

Wolfson School of Mechanical and Manufacturing Engineering

Loughborough University

Loughborough, Leicestershire, LE11 3TU, United Kingdom

Tel: +44 (0) 1509227659

Email: M.Mohammad-Pour@1boro.ac.uk

\section{Acknowledgments}

The authors would like to express their gratitude to ANSOL Company for supplying the TCA software utilized in this study: CALYX.

\section{Definitions/Abbreviations}

a

A

$A_{a}$

$\boldsymbol{C}^{\prime}$

$\boldsymbol{E}_{\boldsymbol{r}}$

$\boldsymbol{E}^{\prime}$

EHL

$\boldsymbol{f}_{v}$

$f_{b}$

$\boldsymbol{h}_{\boldsymbol{c 0}}^{*}$

$\boldsymbol{h}_{c 0}$

K

$\boldsymbol{K}^{\prime}$

$\bar{p}$
Hertzian circular footprint radius

Apparent contact area

Asperity area

Specific heat capacity of

solid

Reduced elastic modulus of the contact

Reduced elastic modulus of the contact: $\left(2 \mathrm{E}_{\mathrm{r}}\right) / \pi$

Elastohydrodynamic

Lubrication

Viscous friction

Boundary friction

Dimensionless central film thickness

Central film thickness

Lubricant thermal

conductivity

Thermal conductivity of solid

Average pressure at contact point
$\boldsymbol{P}_{\boldsymbol{m}}$
Mean pressure
$\boldsymbol{R}$
Radii of curvature at contact point
$\boldsymbol{R}_{\boldsymbol{x}}$
Radii of curvature along the lubricant entrainment direction

$R_{y}$

Radii of curvature along the direction of side leakage

TCA

Tooth Contact Analysis

$U_{r}$

Speed of entraining motion: Rolling velocity

$U_{s}$

Sliding velocity

$\boldsymbol{U}$

Speed of entraining motion

w

Normal Load

$W_{a}$

Asperity load

$\alpha$

Pressure viscosity coefficient

$\beta$

Average asperity tip radius

$\boldsymbol{\varepsilon}$

Slope of the lubricant limiting shear stress-pressure dependence

$\eta$

Lubricant dynamic viscosity at atmospheric pressure

$\lambda$

Stribeck's oil film parameter

$\boldsymbol{\mu}$

$\xi$

Friction coefficient

Asperity density per unit area

$\boldsymbol{\rho}^{\prime}$

Density of solid

$\boldsymbol{\sigma}$

Composite RMS surface roughness

$\sigma_{e}$

Equivalent Stress

$\sigma_{y}$

Yield Stress

$\tau o$

Eyring stress

$\tau_{L}$

Limiting shear stress 